\title{
Biological evaluation of linalool on the function of blood vessels
}

\author{
YUNYU LIANG $^{1}$, YAN ZHONG ${ }^{1}$, XINMEI LI $^{1}$, YINGYING XIAO ${ }^{1}$, YU WU $^{1}$ and PINGCHANG XIE ${ }^{2,3}$ \\ Departments of ${ }^{1}$ Geriatrics and ${ }^{2}$ Emergency, The Second Affiliated Hospital of Guangzhou University of \\ Chinese Medicine; ${ }^{3}$ Provincial Key Laboratory of Research on Emergency in \\ Traditional Chinese Medicine, Guangzhou, Guangdong 510000, P.R. China
}

Received May 27, 2021; Accepted July 30, 2021

DOI: $10.3892 / \mathrm{mmr} .2021 .12514$

\begin{abstract}
Long-term hypertension leads to alterations in the structure and function of blood vessels, and abnormal proliferation and migration of vascular smooth muscle cells (VSMCs) are important factors for these changes. Linalool is a natural compound extracted from plants. The present study aimed to explore the role and underlying mechanism of linalool in the physiological behavior of VSMCs. Angiotensin II (Ang II) was utilized to treat VSMCs, and MTT and western blotting assays were then employed to detect the effect of linalool on the induced proliferation and migration of VSMCs. The target gene of linalool was predicted by the SwissTargetPrediction website, and its expression level in VSMCs was determined using reverse transcription-quantitative PCR and western blotting. Next, the role of the target gene in the physiological behavior of VSMCs treated with linalool was examined, and the signaling pathway was explored. The results revealed that the proliferation and migration of VSMCs treated with Ang II were significantly promoted, and linalool could alleviate these effects in a dose-dependent manner. Cholinergic receptor muscarinic 3 (CHRM3), as a predicted target, was found to be highly expressed in Ang II-induced VSMCs, and CHRM3 overexpression could prevent the inhibitory effect of linalool on cell proliferation and migration. In addition, its overexpression caused an increase in the expression of proteins related to the MAPK signaling pathway. In conclusion, linalool inhibited the proliferation and migration of Ang II-induced VSMCs and blocked the MAPK signaling pathway by downregulating CHRM3.
\end{abstract}

\section{Introduction}

Hypertension is the most common chronic disease, and is characterized by increased systemic arterial blood pressure; it may

Correspondence to: Dr Pingchang Xie, Department of Emergency, The Second Affiliated Hospital of Guangzhou University of Chinese Medicine, 111 Dade Road, Guangzhou, Guangdong 510000, P.R. China

E-mail: pingchangxie@126.com

Key words: linalool, vascular smooth muscle cells, cholinergic receptor muscarinic 3, MAPK, angiotensin II be accompanied by functional damage of other organs, which is the most important risk factor for cardiovascular and cerebrovascular diseases (1). The blood pressure of healthy individuals fluctuates within a certain range along with changes in internal and external environments. In the overall population, the blood pressure levels gradually increase with age, and systolic blood pressure is more pronounced (2), while diastolic blood pressure shows a downward trend after the age of 50 years. Notably, individuals with high risk of hypertension are no longer only elderly patients, since the age of patients is showing a younger trend (3). According to a previous epidemiological study, the number of patients with hypertension worldwide could reach 1.5 billion in 2025 (4). High blood pressure can also cause atherosclerosis (5), cerebral hemorrhage (6), cerebral infarction (7) and other diseases. Since the mechanism remains clear, the clinical condition is mainly managed by antihypertensive drugs; however, these drugs cannot block the progression of hypertension. Therefore, identifying key therapeutic targets is the focus of pre-prevention and post-treatment of hypertension.

Prolonged hypertension can eventually lead to alterations in the structure and function of blood vessels (8), among which, abnormal proliferation and migration of vascular smooth muscle cells (VSMCs) are important factors for such changes (9). VSMCs are the main cell type that constitutes the blood vessel wall, and their main functions are to regulate the structural integrity and vascular tension of blood vessels. In the middle layer of normal mature arteries, VSMCs are in a static state of differentiation, and their synthetic activity and proliferation potential are low (10). However, with vascular injury, the phenotype of VSMCs is altered, as manifested by increased cell proliferation and migration, as well as matrix synthesis (11). Importantly, the changes in the structure and function of VSMCs are the cytopathological basis that leads to a variety of vascular diseases (12). Therefore, exploring the abnormal proliferation and migration of VSMCs has great medical significance for the prevention and control of hypertension.

Linalool is a monoterpene alcohol present in certain aromatic medicinal plants, and its biological activity may affect cardiovascular diseases (13). A previous study showed that the administration of linalool in hypertensive rats could effectively reduce blood pressure and improve hypertension, which may be due to the direct effect on vascular smooth muscle that leads to vasodilation (14). Linalool can also inhibit the malignant cell proliferation of a variety of human malignant solid tumors, including hepatocellular carcinoma, breast cancer, small cell 
carcinoma and malignant melanoma (15). In addition, linalool extracted from eucalyptus leaf essential oil can inhibit breast cancer cell invasion and migration, and downregulate the mRNA and protein expression of epithelial-mesenchymal transition-related factors (including Snail, E-cadherin, N-cadherin and vimentin) (16). Based on these results, it was hypothesized that the effect of linalool on VSMCs could be explored by constructing a hypertensive cell model.

Since angiotensin II (Ang II)-mediated VSMC proliferation plays a crucial role in the structural and functional development of hypertensive blood vessels (17), the present study utilized Ang II to treat VSMCs in order to observe the effect of linalool on the physiological behavior of VSMCs and further explore the underlying mechanism.

\section{Materials and methods}

Cell culture and reagent. The rat thoracic aorta smooth muscle cell line (A7r5) was purchased from Procell Life Science \& Technology Co., Ltd. Cells were incubated in DMEM (Gibco; Thermo Fisher Scientific, Inc.) containing 10\% FBS (Thermo Fisher Scientific, Inc.), 100 U/ml streptomycin and $100 \mathrm{U} / \mathrm{ml}$ penicillin (1\% penicillin/streptomycin), and maintained in a humidified incubator with $5 \% \mathrm{CO}_{2}$ at $37^{\circ} \mathrm{C}$. Linalool and Ang II were obtained from Sigma-Aldrich (Merck KGaA; purity $>95 \%$ ), and were dissolved in DMSO and diluted to the specified concentration according to the experimental requirements.

Cell transfection. A7r5 cells were plated into 6-well plates and cultured until they reached $70-80 \%$ confluence. Cells $\left(2 \times 10^{5}\right)$ well) were transfected with $2 \mu \mathrm{g}$ pcDNA3.1-cholinergic receptor muscarinic 3 (CHRM3) and negative control (NC) vectors (Hanbio Biotechnology Co., Ltd.) using Lipofectamine ${ }^{\circledR} 3000$ reagent (Invitrogen; Thermo Fisher Scientific, Inc.) according to the manufacturer's protocol. At $48 \mathrm{~h}$ post-transfection, the expression levels of CHRM3 were assessed.

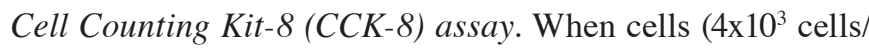
well) were in logarithmic growth phase, several doses of Ang II $\left(10^{-9}, 10^{-8}, 10^{-7}\right.$ and $\left.10^{-6} \mathrm{~mol} / \mathrm{l}\right)$ or linalool solution $(50,100$ and $150 \mu \mathrm{M}$ ) were added to the wells at $37^{\circ} \mathrm{C}$. After $24 \mathrm{~h}$ of incubation, $10 \mu \mathrm{l}$ CCK-8 reagent (Beyotime Institute of Biotechnology) was added to each well of a 96-well plate, and incubation was continued for $1 \mathrm{~h}$. The optical density was determined at $450 \mathrm{~nm}$ using a microplate reader (Thermo Fisher Scientific, Inc.).

MTT assay. A7r5 cells $\left(2 \times 10^{3}\right.$ cells/well) were seeded in 96-well plates and cultured in an incubator containing $5 \% \mathrm{CO}_{2}$ at $37^{\circ} \mathrm{C}$. Cells were treated with Ang II $\left(10^{-7} \mathrm{~mol} / \mathrm{l}\right)$ and different doses of linalool $(50,100$ and $150 \mu \mathrm{M})$ for $0,12,24$ and $48 \mathrm{~h}$ at $37^{\circ} \mathrm{C}$. Next, $200 \mu \mathrm{l}$ MTT solution (Beyotime Institute of Biotechnology) was added to each well, and incubation was continued for $4 \mathrm{~h}$. Subsequently, the medium was removed and DMSO was added. The optical density was determined at a wavelength of $490 \mathrm{~nm}$ using a microplate reader (Thermo Fisher Scientific, Inc.).

Western blotting. RIPA lysis buffer (Beyotime Institute of Biotechnology) was added to the cultured cells, which were then lysed on ice for $30 \mathrm{~min}$. Next, the cells were collected and centrifuged at $14,000 \times \mathrm{g}$ at $4^{\circ} \mathrm{C}$ for $15 \mathrm{~min}$, and the supernatant was aspirated. A BCA protein assay kit (Beyotime Institute of Biotechnology) was then used for protein quantification. Next, heated and denatured protein samples $(25 \mu \mathrm{g})$ were separated via $10 \%$ SDS-PAGE, and then transferred to PVDF membranes. Next, the membranes were blocked in $5 \%$ skimmed milk at room temperature for $1 \mathrm{~h}$, and washed with TBS with $0.05 \%$ Tween-20 (TBST) once for $10 \mathrm{sec}$ at room temperature. Following which, membranes were incubated with the following primary antibodies (1:1,000) overnight at $4^{\circ} \mathrm{C}$ : Anti-proliferating cell nuclear antigen (PCNA; cat. no. ab29; Abcam); anti-MMP2 (cat. no. 40994; Cell Signaling Technology, Inc.); anti-MMP9 (cat. no. 13667; Cell Signaling Technology, Inc.); anti-CHRM3 (cat. no. ab126168; Abcam); anti-phosphorylated (p)-ERK (cat. no. ab192591; Abcam); anti-p-JNK (cat. no. ab215208; Abcam); anti-p-p38 (cat. no. ab178867; Abcam); anti-ERK (cat. no. ab229912; Abcam); anti-JNK (cat. no. ab110724; Abcam); anti-p38 (cat. no. ab182453; Abcam); and anti-GAPDH (cat. no. 5174; Cell Signaling Technology, Inc.). After washing with TBST three times at room temperature, $10 \mathrm{~min}$ per time, the membranes were incubated with HRP-conjugated anti-rabbit (cat. no. ab6721; 1:5,000; Abcam) or anti-mouse antibodies (cat. no. ab6789; 1:10,000; Abcam) for $1 \mathrm{~h}$ at room temperature. Ultra-High Sensitivity ECL kit (cat. no. GK10008; GlpBio Technology) was used to visualize the protein bands, and the results were analyzed with Image Lab software (v3.0; Bio-Rad Laboratories, Inc.).

Wound-healing assay. A7r5 cells $\left(5 \times 10^{5}\right.$ cells/well) were plated into 6 -well plates and incubated at $37^{\circ} \mathrm{C}$ overnight. Sterilized pipette tips were used to make scratches in the cell monolayer when cells grew to $90 \%$ confluence. A wound was generated using a $200-\mu 1$ pipette and plates were washed three times with PBS to remove the extra cells in the wound. Serum-free medium with Ang II $\left(0,1 \times 10^{-7} \mathrm{~mol} / \mathrm{l}\right)$ and linalool $(0,50,100,150 \mu \mathrm{mol} / \mathrm{l})$ was added and incubation was continued. Images were captured under a light microscope (magnification, x100; Olympus Corporation) at 0 and $24 \mathrm{~h}$. Data were analyzed using ImageJ software $(1.52 \mathrm{v}$; National Institutes of Health).

Transwell assay. A7r5 non-transfected or transfected cells were incubated in DMEM at a density of $5 \times 10^{4} \mathrm{cell} / \mathrm{ml}$. A total of $100 \mu \mathrm{l}$ cell suspension was seeded into the upper chamber of Transwell plates (Corning, Inc.), while the lower chamber was filled with $500 \mu \mathrm{l}$ DMEM containing $10 \% \mathrm{FBS}$ for cell culture. After $6 \mathrm{~h}$ of incubation at $37^{\circ} \mathrm{C}, 1 \times 10^{-7} \mathrm{~mol} / \mathrm{l}$ Ang II and linalool $(0,50,100,150 \mu \mathrm{mol} / \mathrm{l})$ were added to treat the cells. After $48 \mathrm{~h}$ of incubation, the cells on the lower side of the Transwell plate were fixed with $4 \%$ formaldehyde and stained with $0.1 \%$ crystal violet solution for $20 \mathrm{~min}$ at room temperature. The number of cells was counted under a light microscope (magnification, x100; Olympus Corporation) and analyzed using ImageJ software $(1.52 \mathrm{v}$; National Institutes of Health).

Reverse transcription-quantitative PCR (RT-qPCR). CHRM3 mRNA expression was detected via RT-qPCR. Total 
A

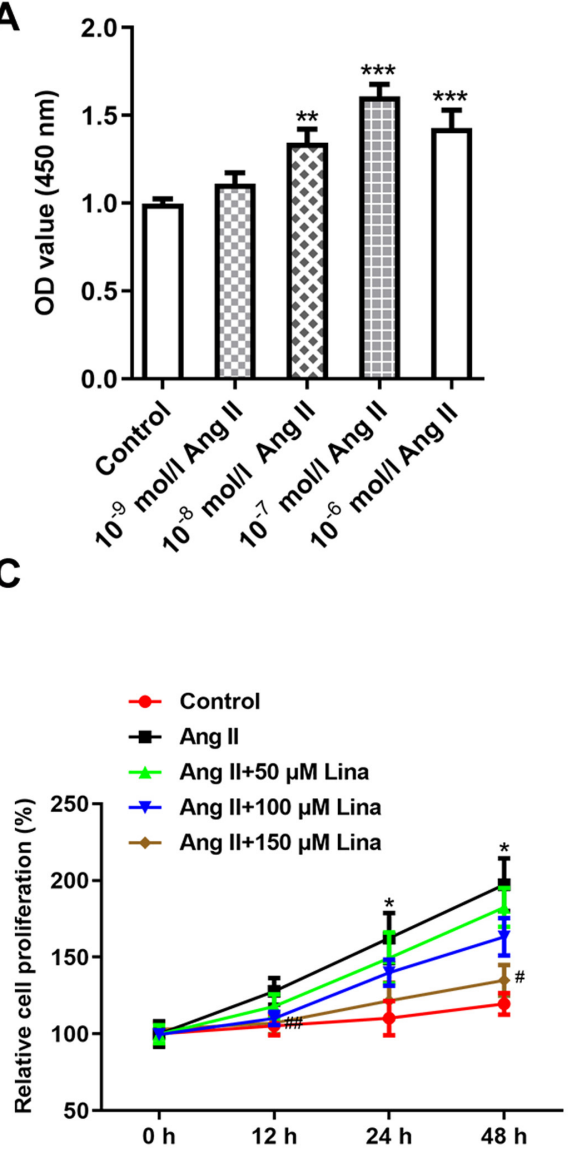

B
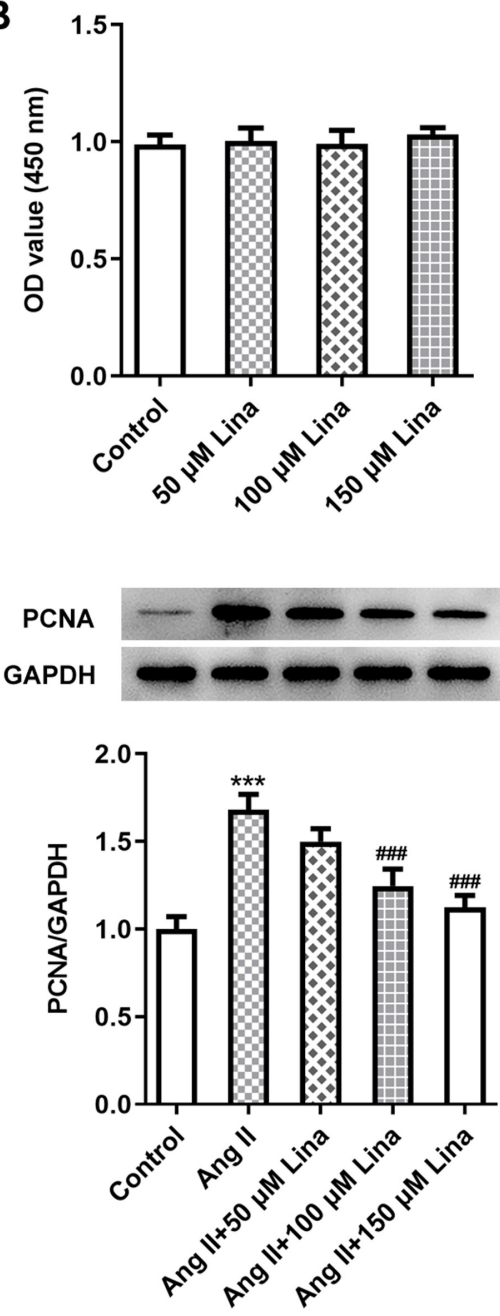

Figure 1. Linalool inhibits the proliferation of Ang II-induced vascular smooth muscle cells. (A) The viability of cells treated with different concentrations of Ang II was detected using a CCK-8 assay. ${ }^{* *} \mathrm{P}<0.01,{ }^{* * *} \mathrm{P}<0.001$ vs. control $(\mathrm{n} \geq 3)$. (B) The viability of cells treated with different concentrations $(50,100,150 \mu \mathrm{mol} / \mathrm{l})$ of linalool was detected using a CCK-8 assay. (C) An MTT assay was used to detect proliferation of A7r5 cells treated by Ang II and linalool ( $\mathrm{n} \geq 3$ ). ${ }^{\text {P }} \mathrm{P}<0.05 \mathrm{vs}$. control; ${ }^{\#} \mathrm{P}<0.05,{ }^{\# \#} \mathrm{P}<0.01$ vs. Ang II ( $\mathrm{n} \geq 3$ ). (D) The expression of PCNA, which is relevant to cell proliferation, was detected via western blotting. ${ }^{* * *} \mathrm{P}<0.001$ vs. control;

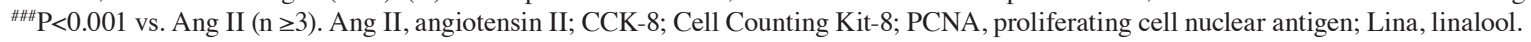

RNA was extracted from cultured A7r5 cells using TRIzol ${ }^{\circledR}$ reagent (Beyotime Institute of Biotechnology). cDNA was transcribed from RNA using a PrimeScript RT Reagent kit (Takara Biotechnology Co., Ltd.). qPCR was subsequently performed using the QuantiTect SYBR ${ }^{\circledR}$ Green PCR kit (Qiagen, Inc.) according to the manufacturer's instructions. The protocol was as follows: RT $\left(42^{\circ} \mathrm{C}\right.$ for $5 \mathrm{~min}$ and then $95^{\circ} \mathrm{C}$ for $10 \mathrm{sec}$ ), followed by an amplification program repeated for 40 cycles $\left(95^{\circ} \mathrm{C}\right.$ for $5 \mathrm{sec}$ and then $60^{\circ} \mathrm{C}$ for $\left.30 \mathrm{sec}\right)$. Data were collected and analyzed using the $2^{-\Delta \Delta C q}$ method (18). Values were normalized against GADPH. The primer sequences were as follows: CHRM3 forward, 5'-TCATCCAGGAGGAAGT ACGG-3' and reverse, 5'-GCTGTGGTCTTGGTCCATCT-3; and GAPDH forward, 5'-GCCCATCACCATCTTCCA GGAG-3' and reverse, 5'- GAAGGGGCGGAGATGATGAC-3'.

Database analysis. SwissTargetPrediction (www.swisstargetprediction.ch) is a website for target prediction of bioactive small molecules. The structure of linalool was uploaded to the website and Homo sapiens was selected. The targets results were displayed after pressing the button 'Predict targets'.
Statistical analysis. GraphPad Prism 8.0 software (GraphPad Software, Inc.) was utilized to analyze the experimental data. All values are represented as the mean \pm SD of triplicate experiments. Unpaired Student's t-test was used to evaluate differences between two groups, and one-way ANOVA followed by Tukey's post hoc test was employed to compare multiple groups. $\mathrm{P}<0.05$ was considered to indicate a statistically significant difference.

\section{Results}

Linalool inhibits the proliferation of Ang II-induced VSMCs. The viability of cells treated with different concentrations of Ang II was detected using a CCK-8 assay. The experimental concentration range of Ang II was $1 \times 10^{-9}-1 \times 10^{-6} \mathrm{~mol} / 1$. The number of viable cells increased in a concentration-dependent manner until the concentration of Ang II reached $1 \times 10^{-7} \mathrm{~mol} / \mathrm{l}$. When the concentration continued to increase, the number of viable cells did not increase further. This may be due to the excessive concentration that caused damage to cells (Fig. 1A). Thus, Ang II at a concentration of $1 \times 10^{-7} \mathrm{~mol} / \mathrm{l}$ was selected to 
A
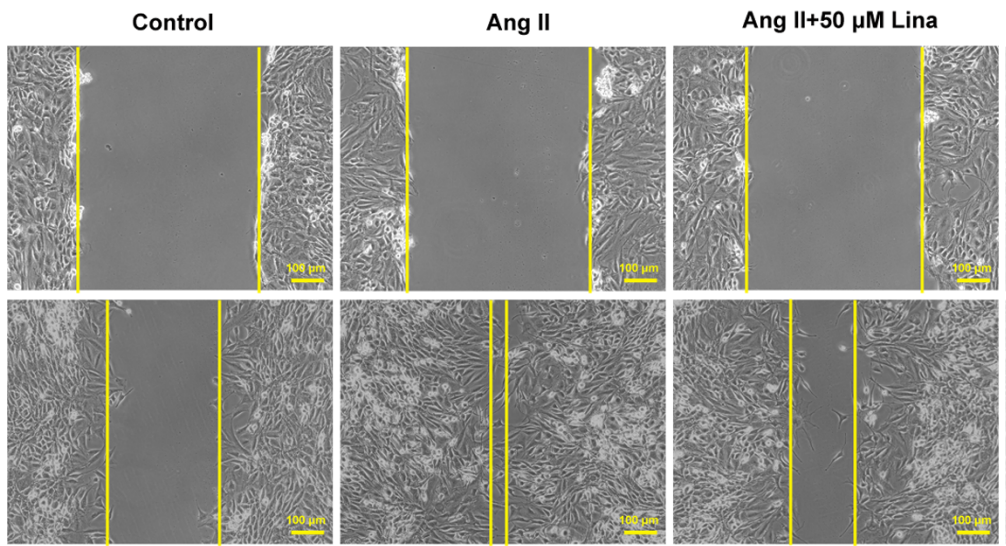

Ang II

B

Ang $11+50 \mu \mathrm{M}$ Lina
Ang $\mathrm{II}+100 \mu \mathrm{M}$ Lina
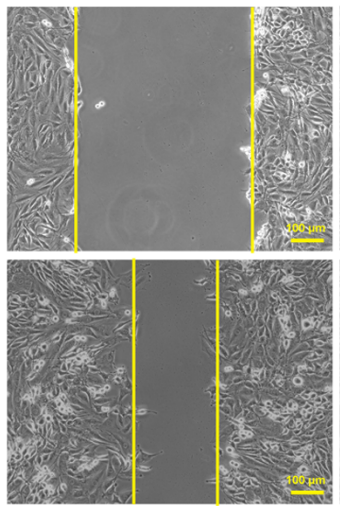

Ang $\mathrm{II}+100 \mu \mathrm{M}$ Lina
Ang $I+150 \mu \mathrm{M}$ Lina

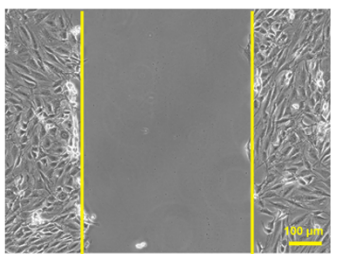

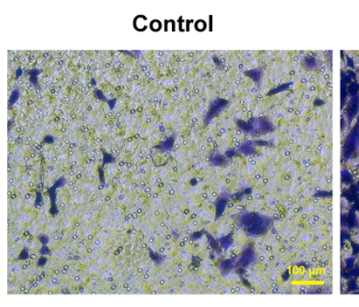
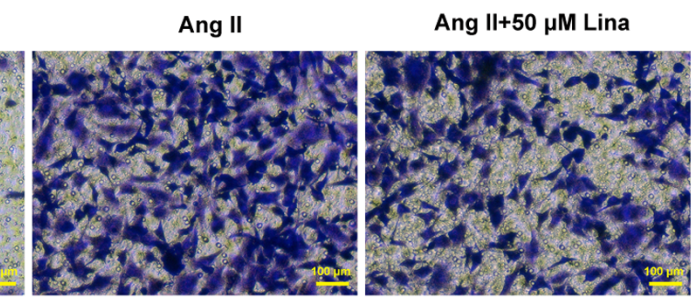

E MMP2

C

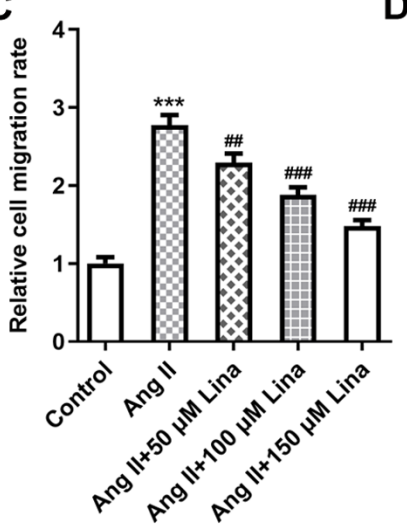

D

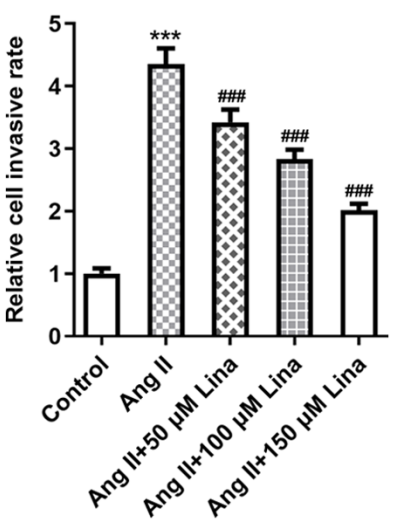

GAPDH

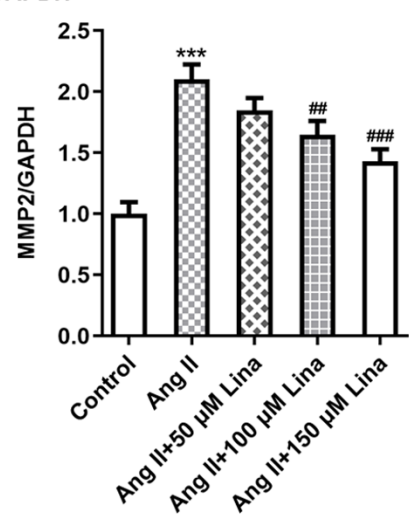

Ang $\|+150 \mu \mathrm{M}$ Lina

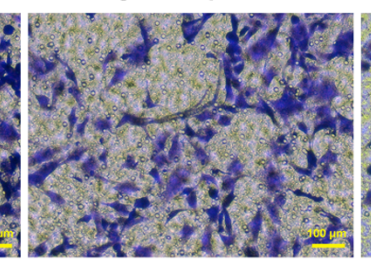

$F_{\text {MMP9 }}$

GAPDH

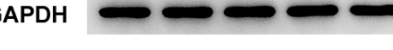

Figure 2. Linalool inhibits the migration of Ang II-induced vascular smooth muscle cells. (A) Wound-healing and (B) Transwell assays were applied to evaluate cell migration. Scale bar, $100 \mu \mathrm{m}$. (C) Quantitative results of wound-healing and (D) Transwell assay. (E and F) The expression levels of MMP2

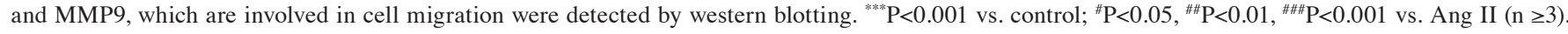
Ang II, angiotensin II.

treat A7r5 cells in subsequent experiments. A similar method was employed to detect the effect of linalool on cell viability. Linalool at a concentration of 50-150 $\mu \mathrm{mol} / 1$ had no effect on cell viability (Fig. 1B).

In addition, an MTT assay was used to detect the proliferation of A7r5 cells treated with Ang II and linalool. The number of cells treated with Ang II almost doubled at $48 \mathrm{~h}$ compared with the control, while the proliferation of the cells treated with linalool for the same time was inhibited compared with the Ang II group. Compared with that of cells treated with Ang II alone, the proliferation rate of groups treated with linalool additionally showed a concentration-dependent decrease (Fig. 1C). PCNA plays a role in cell cycle regulation and/or DNA replication, and is an objective indicator for evaluating cell proliferation (19); therefore, its expression level in each group of cells was determined via western blotting. The results revealed that the expression of PCNA in groups treated with linalool additionally decreased in comparison with that in the Ang II-treated group (Fig. 1D).

Linalool inhibits the migration of Ang II-induced VSMCs. Wound-healing and Transwell assays were applied to determinate cell migration. The wounds of cells treated with Ang II alone were filled with numerous cells, while those of cells simultaneously treated with linalool exhibited a lower number of cells. Cells treated with linalool at a concentration of $150 \mu \mathrm{mol} / 1$ showed the least number of migrated cells (Fig. 2A and C).

Similarly, in the Transwell assay, the cells in the Ang II group that migrated to the lower chamber were densely packed, while in the group with the highest experimental concentration of linalool, the number of migrated cells was the least (Fig. 2B and D). The expression levels of MMP2 and MMP9 were detected by western blotting as they are 
A

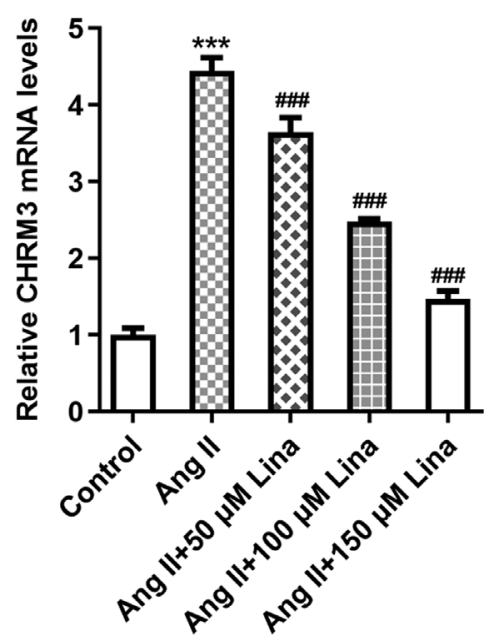

B

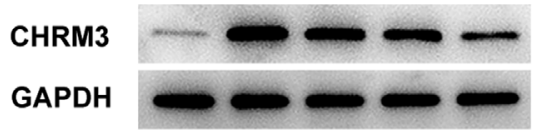

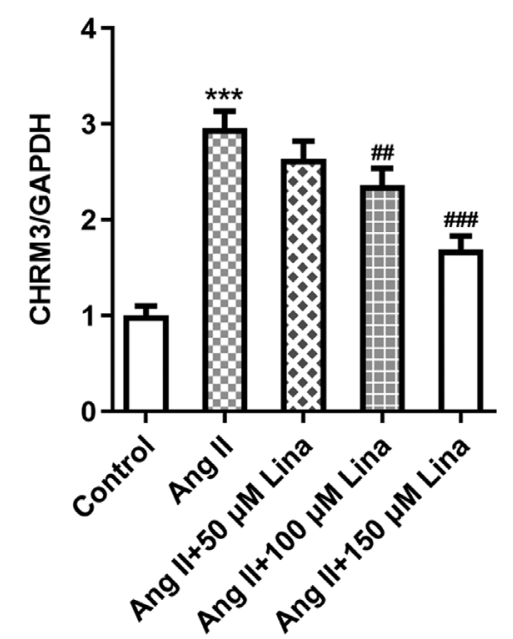

Figure 3. Linalool downregulates CHRM3 expression in Ang II-induced vascular smooth muscle cells. (A) Reverse transcription-quantitative PCR and (B) western blotting were used to detect CHRM3 expression in cells treated with Ang II and different concentrations of linalool. ${ }^{* * *} \mathrm{P}<0.001$ vs. control; ${ }^{\# \#} \mathrm{P}<0.01,{ }^{\# \#} \mathrm{P}<0.001$ vs. Ang II ( $\mathrm{n} \geq 3$ ). Ang II, angiotensin II; CHRM3, cholinergic receptor muscarinic 3.

indicators of migration (20), and they exhibited a decline in the presence of linalool in a concentration-dependent manner compared with the Ang II group (Fig. 2E and F).

Linalool downregulates CHRM3 expression in Ang II-induced VSMCs. CHRM3 was the target of linalool predicted by the SwissTargetPrediction website. RT-qPCR and western blotting were used to detect CHRM3 expression in cells treated with Ang II and different concentration of linalool. CHRM3 was lowly expressed in normal A7r5 cells, and once the cells were stimulated with Ang II, its expression significantly increased compared with the control group, while the addition of linalool significantly decreased the expression of CHRM3 in a concentration-dependent manner compared with the Ang II group (Fig. 3A and B).

Linalool inhibits the proliferation and migration of Ang II-induced VSMCs by downregulating CHRM3 expression. In order to study whether CHRM3 is involved in the inhibitory mechanism of linalool, RT-qPCR and western blotting were employed to detect the expression level of CHRM3 in transfected cells. The results confirmed the efficiency of transfection (Fig. 4A and B). Based on the aforementioned experiments, linalool at a concentration of $150 \mu \mathrm{mol} / 1$ was used to treat transfected cells. The inhibitory effect of linalool on the proliferation of non-transfected cells was blocked. The cell proliferation of the Ang II+linalool+pcDNA3.1-CHRM3 group was higher than that of the Ang II+linalool+pcDNA3.1-NC group, indicating that $\mathrm{CHRM} 3$ overexpression could affect the function of linalool (Fig. 4C). Furthermore, PCNA expression was increased in the Ang II+linalool+pcDNA3.1-CHRM3 group compared with the Ang II+linalool+pcDNA3.1-NC group (Fig. 4D). The migratory ability and protein expression of the transfected cells were determined (Fig. 5A-F). Similar results were observed regarding the migratory ability of the cells, indicating that linalool achieved its effect on cell proliferation and migration by regulating CHRM3.

Linalool blocks the MAPK signaling pathway by downregulating CHRM3 expression. To estimate whether linalool regulates cell proliferation and migration via the MAPK signaling pathway, western blotting was applied to detect the expression of MAPK-related proteins in A7r5 and transfected cells. The expression levels of p-ERK, p-JNK and p-p38 in Ang II-induced A7r5 cells were decreased when cells were treated with Ang II+linalool, indicating that linalool suppressed the activation of MAPK signaling. The expression levels of these proteins in the Ang II+linalool+pcDNA3.1-CHRM3 group were increased compared with the Ang II+linalool+pcDNA3.1-NC group, with levels almost restored to the expression levels in cells treated with only Ang II (Fig. 6A and B). These results suggested that linalool hindered the MAPK signaling pathway by regulating CHRM3.

\section{Discussion}

VSMC proliferation is considered to be a common cause of vascular proliferative diseases, including hypertension (21), atherosclerosis (22) and restenosis after balloon angioplasty (23), which are the most common cardiovascular diseases worldwide and the main causes of mortality. Prolonged hypertension can cause VSMC proliferation and fibrosis inside the arteries, leading to narrowing of the vessel wall (24). Therefore, developing a therapeutic target that can alleviate the proliferation and migration of VSMCs is an important strategy, which has medical relevance for the treatment of vascular diseases. The present study applied Ang II to induce VSMCs to establish a research model. After induction, the proliferation and migration of cells were obviously abnormal, which allowed for the investigation 
A

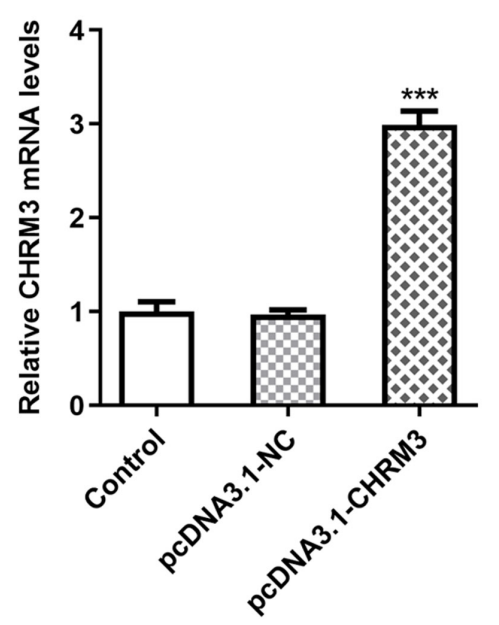

C

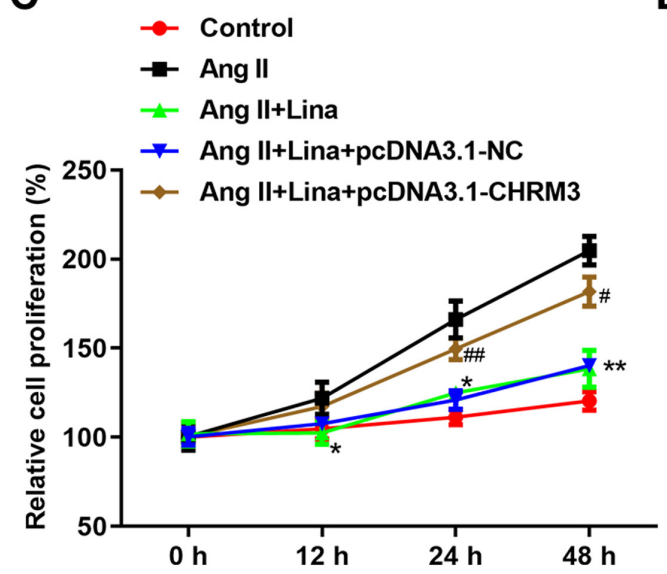

B
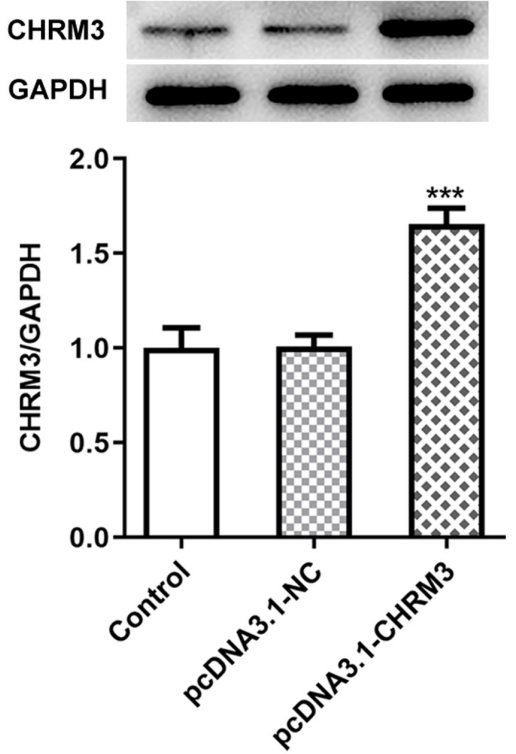

D PCNA $-\infty-\infty-$

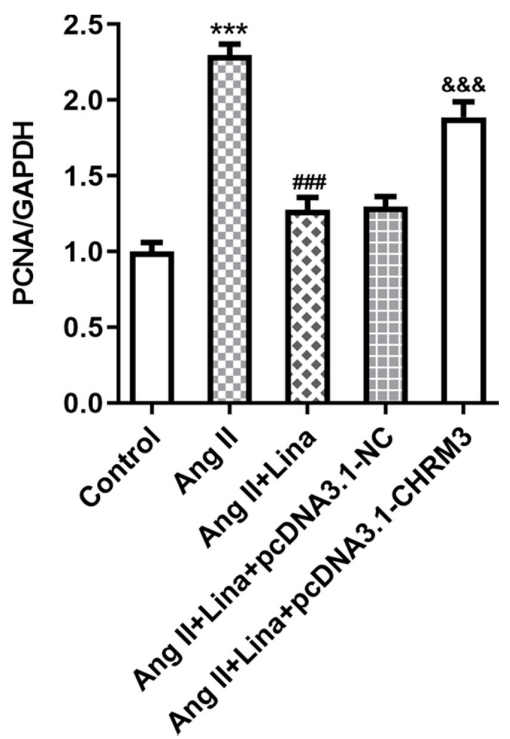

Figure 4. Linalool inhibits the proliferation of Ang II-induced vascular smooth muscle cells via downregulating CHRM3 expression. (A) Reverse transcription-quantitative PCR and (B)western blotting were employed to detect the expression level of CHRM3 in transfected cells. ${ }^{* * *} \mathrm{P}<0.001$ vs. pcDNA3.1-NC ( $\geq 3$ ). (C) MTT assay was used to detect cell proliferation. ${ }^{*} \mathrm{P}<0.05,{ }^{* *} \mathrm{P}<0.01$ vs. Ang II; ${ }^{\#} \mathrm{P}<0.05$, ${ }^{\# \prime} \mathrm{P}<0.01$ vs. Ang II+linalool+pcDNA3.1-NC (n $\geq 3$ ). (D) The expression of PCNA, which is relevant to cell proliferation, was detected via western blotting. ${ }^{* * *} \mathrm{P}<0.001$ vs. control; ${ }^{\# \# \#} \mathrm{P}<0.001 \mathrm{vs}$. Ang II; \&\&\& $\mathrm{P}<0.001 \mathrm{vs}$. Ang II+lin alool+pcDNA3.1-NC ( $\mathrm{n} \geq 3)$. Ang II, angiotensin II; CHRM3, cholinergic receptor muscarinic 3; NC, negative control; PCNA, proliferating cell nuclear antigen; $\mathrm{NC}$, negative control.

of the possible effects of linalool on VSMCs. The results showed that the maximum experimental concentration of linalool $(150 \mu \mathrm{M})$ had no effect on normal VSMC viability, while linalool inhibited the proliferation and migration of induced VSMCs.

The present study also explored the potential mechanism of linalool. CHRM3, the target of linalool predicted by the SwissTargetPrediction website, is a protein-coding gene. This muscarinic cholinergic receptor belongs to a larger family of $\mathrm{G}$ protein-coupled receptors. The functional diversity of these receptors is determined by their binding to acetylcholine (25), in which CHRM3 regulates smooth muscle contraction (26), and its stimulation causes the secretion of glandular tissue. Diseases associated with CHRM3 include Prune syndrome (27) and cholinergic urticaria (28). CHRM3 coding variants can increase muscarinic cholinergic 3 receptor (M3R) signaling, which is associated with higher blood pressure. Removal of M3R signals leads to lower blood pressure and improves heart and kidney dysfunction (29). In addition, CHRM3 is upregulated in a large part of benign prostatic hyperplasia (BPH) tissue, and the activation of CHRM3 also promotes the proliferation 
A

$\mathbf{O h}$

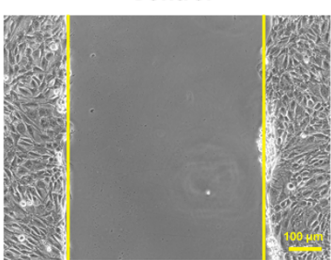

$48 \mathrm{~h}$

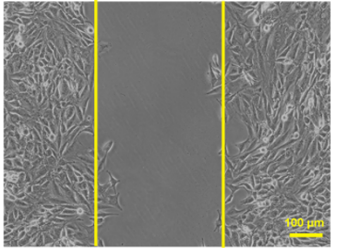

B

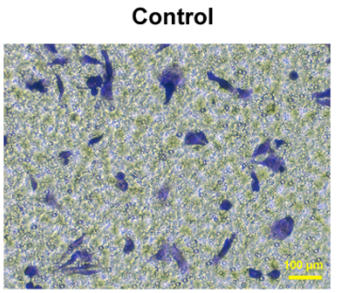

Ang II

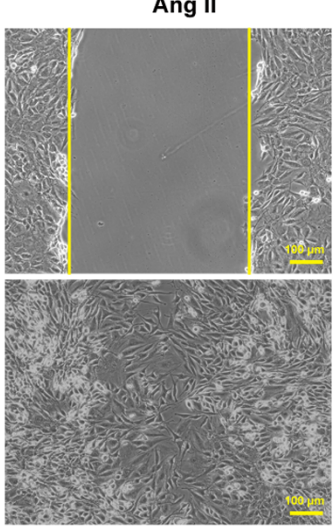

Ang II

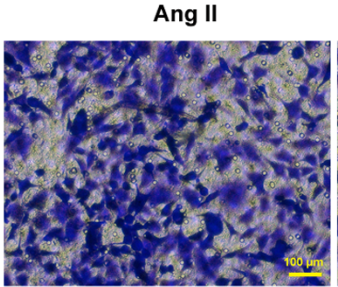

Ang $\|+$ Lina
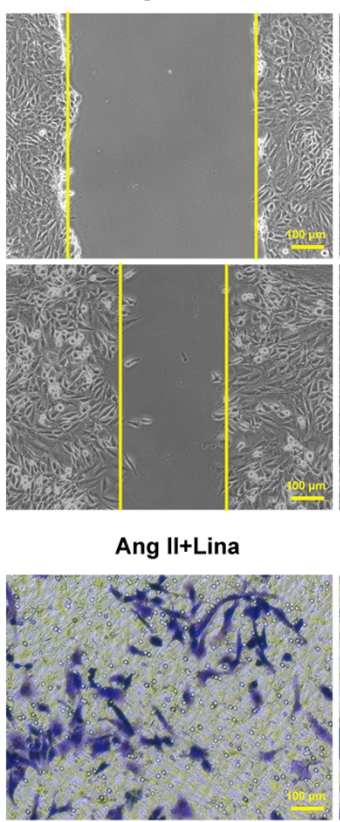

Ang II+Lina+pcDNA3.1-NC Ang II+Lina+pcDNA3.1-CHRM3

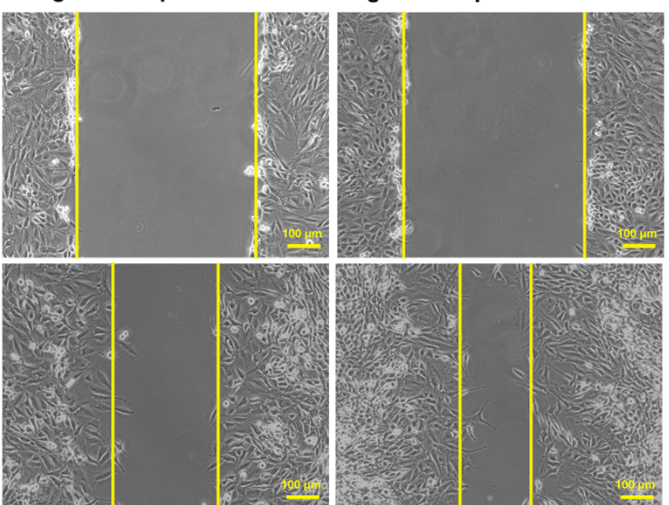

Ang II+Lina+pcDNA3.1-NC Ang II+Lina+pcDNA3.1-CHRM3

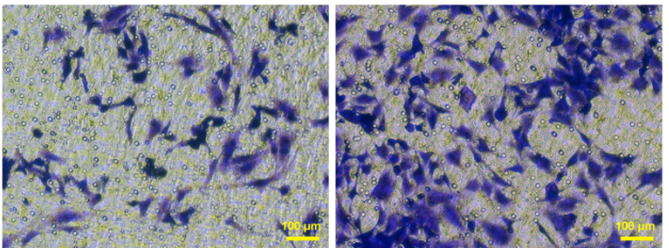

E MMP2

GAPDH

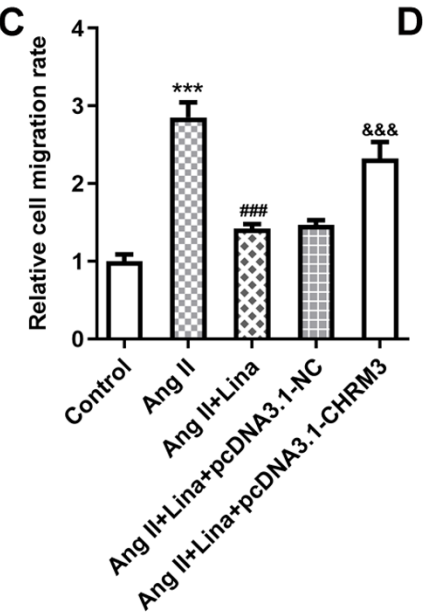

D

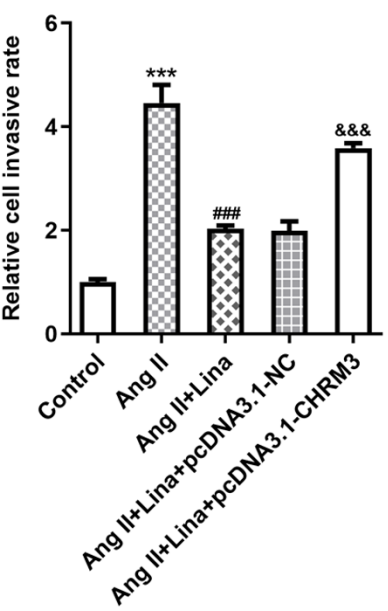

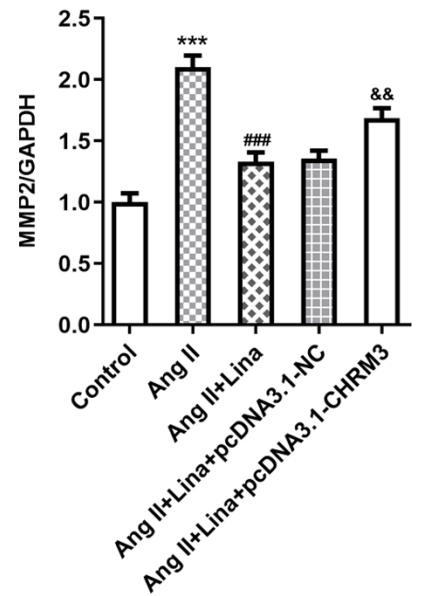

$F_{\text {MMP9 }}$

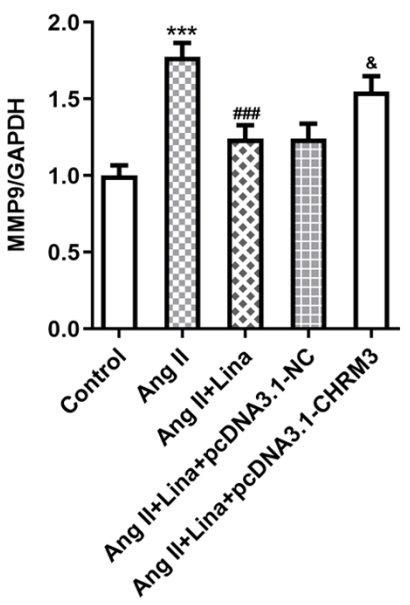

Figure 5. Linalool inhibits the migration of Ang II-induced vascular smooth muscle cells via downregulating the expression of CHRM3. (A) Wound-healing and (B) Transwell assays were applied to determinate cell migration. Scale bar, $100 \mu \mathrm{m}$. (C) Quantitative results of wound-healing and (D) Transwell assay. (E and F) The expression levels of MMP2 and MMP9, which are relevant to cell migration, were detected by western blotting. ${ }^{* * *} \mathrm{P}<0.001$ vs. control; ${ }^{\# \# \# ~} \mathrm{P}<0.001$ vs. Ang II; ${ }^{\&} \mathrm{P}<0.05,{ }^{\&} \mathrm{P}<0.01,{ }^{\& \&} \mathrm{P}<0.001$ vs. Ang II+linalool+pcDNA3.1-NC (n $\left.\geq 3\right)$. Ang II, angiotensin II; CHRM3, cholinergic receptor muscarinic 3; $\mathrm{NC}$, negative control.

of BPH cells (30). Overexpression of CHRM3 or activation of CHRM3 by carbachol promotes further cell proliferation, migration and castration resistance (31). In the present study, CHRM3 overexpression was found to promote the proliferation and migration of VSMCs, and to inhibit the suppressive effect of linalool on cell hyperplasia. This indicated that linalool exerts its inhibitory role by downregulating CHRM3.

Furthermore, the expression level of proteins related to the MAPK signaling pathway in VSMCs was found to decrease with linalool treatment, indicating that linalool played a role by blocking MAPK signaling. CHRM3 overexpression reversed the decline, indicating that CHRM3 mediated this pathway. Linalool was found to block the MAPK signaling pathway by downregulating CHRM3. This association has also been verified in other studies where CHRM3 mediates the MAPK signaling pathway. For example, upregulation of microRNA-30e inhibits the MAPK signaling pathway and its downstream genes by downregulating CHRM3 in prostate cancer cells (32), suggesting that CHRM3 can regulate the MAPK signaling pathway. Since the MAPK signaling pathway is a universal pathway for cell proliferation, differentiation and migration (33), after using Ang II to induce abnormal cell proliferation, the present study explored the underlying mechanism of linalool from the perspective of this pathway. When the whole mechanism was reviewed, the Ang II receptor caught our attention. We propose that linalool achieved inhibitory effects by blocking the Ang II receptor. 
A
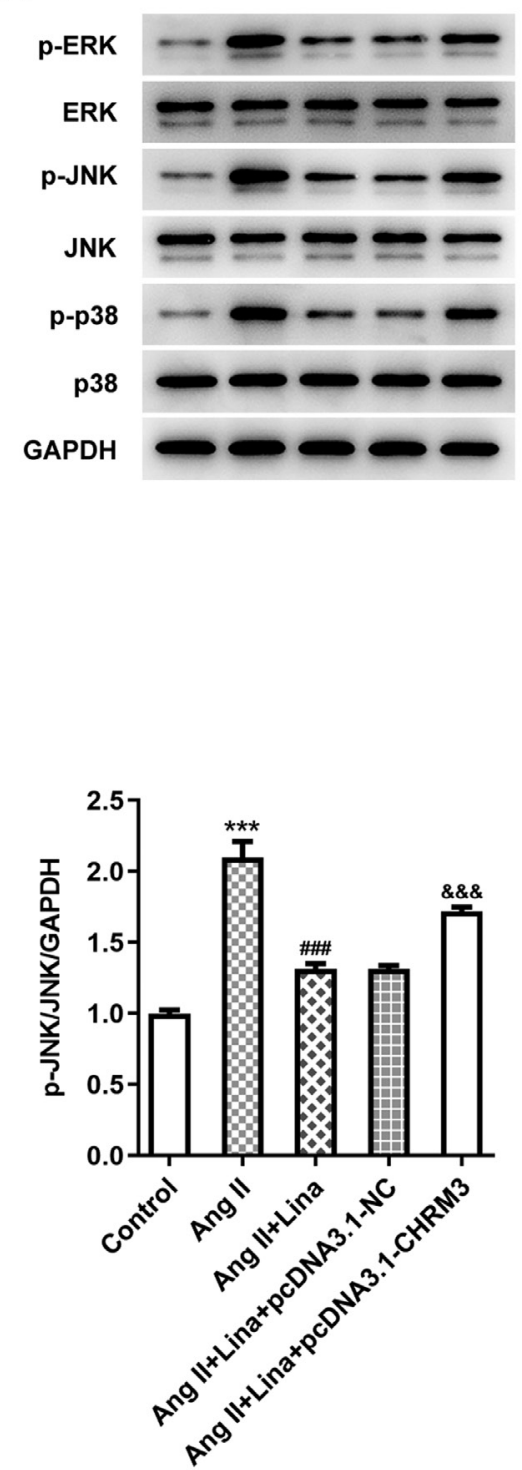

B
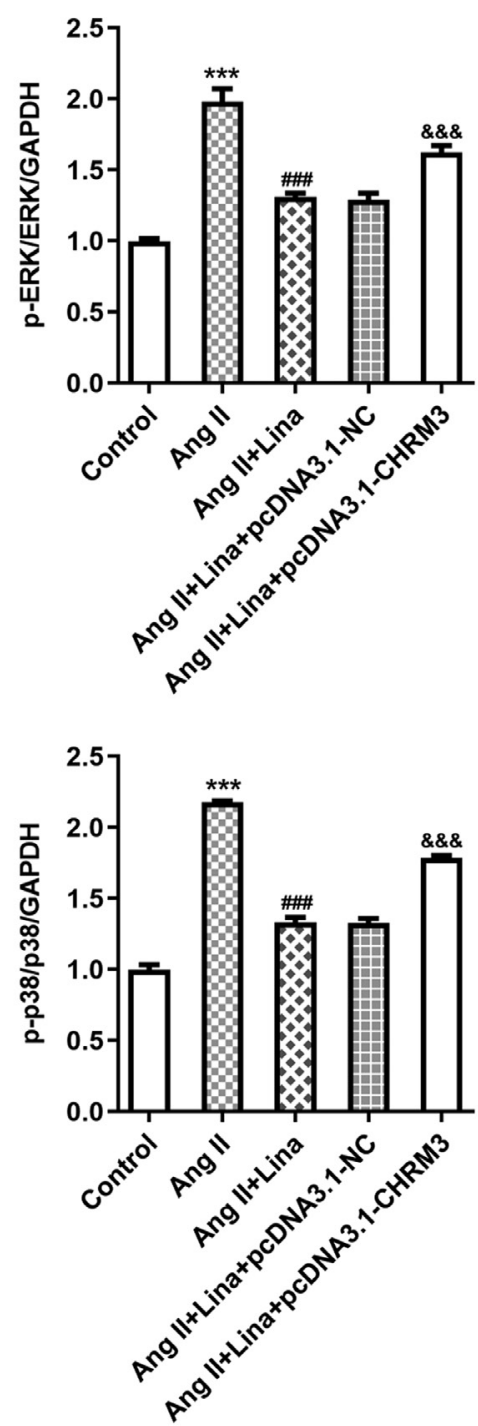

Figure 6. Linalool blocks the MAPK signaling pathway via downregulating the expression of CHRM3. (A) Western blotting was applied to detect the expression of proteins related to the MAPK signaling pathway in A7r5 and transfected cells. (B) The semi-quantitative graphs of western blotting. ${ }^{* * * *} \mathrm{P}<0.001$ vs. control; ${ }^{\# \# /} \mathrm{P}<0.001$ vs. Ang II; \&\&\& $\mathrm{P}<0.01$ vs. Ang II+linalool+pcDNA3.1-NC ( $\mathrm{n} \geq 3$ ). Ang II, angiotensin II; CHRM3, cholinergic receptor muscarinic 3; NC, negative control; p-, phosphorylated.

This can be regarded as a novel viewpoint for research, which will be the direction of our future research.

In conclusion, linalool was demonstrated to block the MAPK signaling pathway by downregulating the expression of CHRM3, thereby inhibiting the proliferation and migration of Ang II-induced VSMCs. The present findings suggested a potential role of linalool in inhibiting VSMC hyperplasia, although the specific mechanisms involved remain to be further explored.

\section{Acknowledgements}

Not applicable.

\section{Funding}

No funding was received.

\section{Availability of data and materials}

The datasets used and/or analyzed during the current study are available from the corresponding author on reasonable request.

\section{Authors' contributions}

YL and XL designed the study and wrote the manuscript. YZ, YX, YW and PX performed the experiments and analyzed the data. PX examined the data and critically revised the manuscript for important intellectual content. All authors confirm the authenticity of all the raw data. All authors have read and approved the final manuscript.

\section{Ethics approval and consent to participate}

Not applicable. 


\section{Patient consent for publication}

Not applicable.

\section{Competing interests}

The authors declare that they have no competing interests.

\section{References}

1. Czuriga-Kovács KR, Czuriga D and Csiba L: Influence of Hypertension, Alone and in Combination with Other Vascular Risk Factors on Cognition. CNS Neurol Disord Drug Targets 15: 690-698, 2016

2. Strandberg TE and Pitkala K: What is the most important component of blood pressure: Systolic, diastolic or pulse pressure? Curr Opin Nephrol Hypertens 12: 293-297, 2003.

3. Kawabe H, Azegami T, Takeda A, Kanda T, Saito I, Saruta T and Hirosi H: Features of and preventive measures against hypertension in the young. Hypertens Res 42: 935-948, 2019.

4. Devos P and Menard J: Bibliometric analysis of research relating to hypertension reported over the period 1997-2016. J Hypertens 37: 2116-2122, 2019.

5. Hurtubise J, McLellan K, Durr K, Onasanya O, Nwabuko D and NdisAng JF: The Different Facets of Dyslipidemia and Hypertension in Atherosclerosis. Curr Atheroscler Rep 18: 82, 2016.

6. Chamarro R, Ponz A, Alonso MD, Gil R and Laínez JM: [Arterial hypertension and intracerebral hemorrhage]. Neurologia 18 731-739, 2003.

7. Turin TC, Okamura T, Afzal AR, Rumana N, Watanabe M, Higashiyama A, Nakao Y, Nakai M, Takegami M, Nishimura $\mathrm{K}$, et al: Hypertension and lifetime risk of stroke. J Hypertens 34: 116-122, 2016.

8. Arribas SM, Hinek A and González MC: Elastic fibres and vascular structure in hypertension. Pharmacol Ther 111: 771-791, 2006.

9. Shi L, Tian C, Sun L, Cao F and Meng Z: The lncRNA TUG1/ miR-145-5p/FGF10 regulates proliferation and migration in VSMCs of hypertension. Biochem Biophys Res Commun 501: 688-695, 2018.

10. Owens GK, Kumar MS and Wamhoff BR: Molecular regulation of vascular smooth muscle cell differentiation in development and disease. Physiol Rev 84: 767-801, 2004.

11. Herring BP, Hoggatt AM, Burlak C and Offermanns S: Previously differentiated medial vascular smooth muscle cells contribute to neointima formation following vascular injury. Vasc Cell 6: 21 , 2014.

12. Montezano AC, Nguyen Dinh Cat A, Rios FJ and Touyz RM: Angiotensin II and vascular injury. Curr Hypertens Rep 16: 431, 2014.

13. Pereira I, Severino P, Santos AC, Silva AM and Souto EB: Linalool bioactive properties and potential applicability in drug delivery systems. Colloids Surf B Biointerfaces 171: 566-578, 2018.

14. Anjos PJ, Lima AO, Cunha PS, De Sousa DP, Onofre AS, Ribeiro TP, Medeiros IA, Antoniolli AR, Quintans-Júnior LJ and Santosa MR: Cardiovascular effects induced by linalool in normotensive and hypertensive rats. Z Naturforsch C J Biosci 68 : 181-190, 2013

15. Gong X, WAng B, Yan L, Lu X and Zhao X: Linalool inhibits the growth of human $T$ cell acute lymphoblastic leukemia cells with involvement of the MAPK signaling pathway. Oncol Lett 20: 181, 2020.

16. Xing X, Ma JH, Fu Y, Zhao H, Ye XX, Han Z, Jia FJ and Li X: Essential oil extracted from erythrina corallodendron L. leaves inhibits the proliferation, migration, and invasion of breast cancer cells. Medicine (Baltimore) 98: e17009, 2019.
17. Eguchi S, Kawai T, Scalia R and Rizzo V: Understanding Angiotensin II Type 1 Receptor Signaling in Vascular Pathophysiology. Hypertens 71: 804-810, 2018.

18. Livak KJ and Schmittgen TD: Analysis of relative gene expression data using real-time quantitative PCR and the 2(-Delta Delta C(T)) Method. Methods 25: 402-408, 2001.

19. Strzalka W and Ziemienowicz A: Proliferating cell nuclear antigen (PCNA): A key factor in DNA replication and cell cycle regulation. Ann Bot (Lond) 107: 1127-1140, 2011.

20. Urrutia G, Laurito S, Campoy E, Nasif D, Branham MT and Roqué M: PAX6 Promoter Methylation Correlates with MDA-MB-231 Cell Migration, and Expression of MMP2 and MMP9. Asian Pac J Cancer Prev 19: 2859-2866, 2018.

21. FAng G, Qi J, HuAng L and Zhao X: LncRNA MRAK048635_P1 is critical for vascular smooth muscle cell function and phenotypic switching in essential hypertension. Biosci Rep 39: 39, 2019.

22. Basatemur GL, Jørgensen HF, Clarke MCH, Bennett MR and Mallat Z: Vascular smooth muscle cells in atherosclerosis. Nat Rev Cardiol 16: 727-744, 2019

23. Jun MY, Karki R, Paudel KR, Sharma BR, Adhikari D and Kim DW: Alkaloid rich fraction from Nelumbo nucifera targets VSMC proliferation and migration to suppress restenosis in balloon-injured rat carotid artery. Atherosclerosis 248: 179-189, 2016.

24. Liao H, Gong J, ZhAng W and Guo X: Valsartan inhibits Angiotensin II-induced proliferation of vascular smooth muscle cells via regulating the expression of mitofusin 2. J Huazhong Univ Sci Technolog Med Sci 32: 31-35, 2012.

25. Borroto-Escuela DO, AgnatiLF, Fuxe K and Ciruela F: Muscarinic acetylcholine receptor-interacting proteins (mAChRIPs): Targeting the receptorsome. Curr Drug Targets 13: 53-71, 2012.

26. Kruse AC, Hu J, Kobilka BK and Wess J: Muscarinic acetylcholine receptor X-ray structures: Potential implications for drug development. Curr Opin Pharmacol 16: 24-30, 2014.

27. Beaman GM, Galatà G, Teik KW, Urquhart JE, Aishah A, O'Sullivan J, Bhaskar SS, Wood KA, Thomas HB, O'Keefe RT, et al: A homozygous missense variant in CHRM3 associated with familial urinary bladder disease. Clin Genet 96: 515-520, 2019.

28. Tokura Y: New Etiology of Cholinergic Urticaria. Curr Probl Dermatol 51: 94-100, 2016.

29. Deng AY, deBlois D, Laporte SA, Gelinas D, Tardif JC, Thorin E, Shi Y, Raignault A and Menard A: Novel Pathogenesis of Hypertension and Diastolic Dysfunction Caused by M3R (Muscarinic Cholinergic 3 Receptor) Signaling. Hypertens 72: 755-764, 2018.

30. WAng N, Dong BJ, Quan Y, Chen Q, Chu M, Xu J, Xue W, HuAng YR, YAng R and Gao WQ: Regulation of Prostate Development and Benign Prostatic Hyperplasia by Autocrine Cholinergic Signaling via Maintaining the Epithelial Progenitor Cells in Proliferating Status. Stem Cell Reports 6: 668-678, 2016.

31. WAng N, Yao M, Xu J, Quan Y, ZhAng K, YAng R and Gao WQ: Autocrine Activation of CHRM3 Promotes Prostate Cancer Growth and Castration Resistance via CaM/CaMKK-Mediated Phosphorylation of Akt. Clin Cancer Res 21: 4676-4685, 2015.

32. Zheng XM, ZhAng P, Liu MH, Chen P and ZhAng WB: MicroRNA-30e inhibits adhesion, migration, invasion and cell cycle progression of prostate cancer cells via inhibition of the activation of the MAPK signaling pathway by downregulating CHRM3. Int J Oncol 54: 443-454, 2019.

33. Sun Y, Liu WZ, Liu T, Feng X, YAng N and Zhou HF: Signaling pathway of MAPK/ERK in cell proliferation, differentiation, migration, senescence and apoptosis. J Recept Signal Transduct Res 35: 600-604, 2015.

This work is licensed under a Creative Commons Attribution-NonCommercial-NoDerivatives 4.0 International (CC BY-NC-ND 4.0) License. 